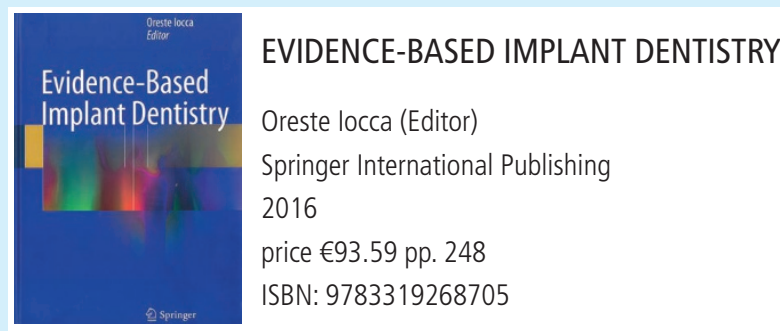

Evidence-Based Implant Dentistry presents up-to-date information that reflects the highest level of scientific evidence as presented in the studied literature. This book is available as a textbook or eBook. It is aimed at dental students, general dental practitioners and implant specialists who wish to update their knowledge on implantology or learn more about the topic. It is structured in an organised, easy to use format allowing specific topics to be easily located from the contents page. Each topic is presented with facts accompanied by clear diagrams and clinical photographs encapsulating information. Among the topics addressed by expert authors are the bibliographic tools used for literature searches, statistical concepts, prognosis of natural tooth versus implant restorations, bone response to implant treatment, placement and loading time, implant design and length, platform design, implant abutments, prosthodontic treatment, reconstructive surgery, and peri-implantitis. This 248 page book firstly considers the evidence base and then provides the reader with trustworthy and scientifically supported information to current implant treatment and key issues in the field.

The book starts off with two chapters dedicated to evidencebased hierarchy and common statistical tools required to fully understand and appraise literature. Chapter 3 is an excellent guide to various clinical scenarios in regard to extraction or implants. It uses easy to read schematic approaches and treatment algorithms to aid the decision-making process. Chapters 4 to 11 go through a great level of detail regarding different concepts, techniques and materials regarding the implant process and complications.

My overall impression of this book is that there is an almost overwhelming amount of literature reviews quoted with statistics. However, it expertly uses the information to help manage important clinical scenarios. This book uses a simplistic approach describing many case examples and diagrams portrayed in many chapters providing a useful adjunct to the text. The diagrams also help to split up the written prose making reading easier. The box at the start of each chapter providing an overview of its structure and objectives is particularly useful. The authors have taken on the task of searching through the latest evidence and applying it effectively in clinical practice. This book would primarily benefit an implant specialist. It provides a wealth of information on implants, however, it is still within the scope of the general dentist and dental students. The amount of data available not only in the field of implantology but in general dentistry is huge and constantly increasing and so the evidence-based approach is useful for clinicians who need to be able to appraise an ever increasing amount of different literature in order to identify the best materials and approaches, even if they are not dealing with implants on a daily basis. This book is extremely useful in understanding the principles of evidence-based dentistry. In summary, it is an extremely useful resource.

P. Sinnott

\title{
Conference celebrates wide-ranging achievements
}

The British Dental Conference and Exhibition took place from 25-27 May in Manchester's Central Convention Complex. The event saw the inauguration of the BDA President for 2017-18, Peter Dyer. Peter is currently chair of the Central Committee for Hospital Dental Services (CCHDS). Former BDA Chair Susie Sanderson was confirmed as the President Elect for 2018-19. The event also saw the launch by BDA Chair Mick Armstrong of the BDA's We Are Dentistry campaign, celebrating the wide ranging achievements of dental professionals and calling on colleagues to share their stories, and show the difference dentists are making in their communities. The campaign video has already been viewed over 6,000 times.

Further highlights were the Honours \& Awards dinner at Manchester Town Hall (pictured) celebrating the contribution of individuals and groups across the dental industry; a successful young dentist reception on Thursday evening; and panel discussions covering contract reform and regulation changes across dentistry. Following the tragic events earlier in the week the Association pledged $£ 5,000$ to the Manchester Evening
News We Stand Together fund supporting the victims of the Manchester Arena attack.

Save the date for next year's BDA

Conference and Exhibition: Thursday 10 to Saturday 12 May 2018.

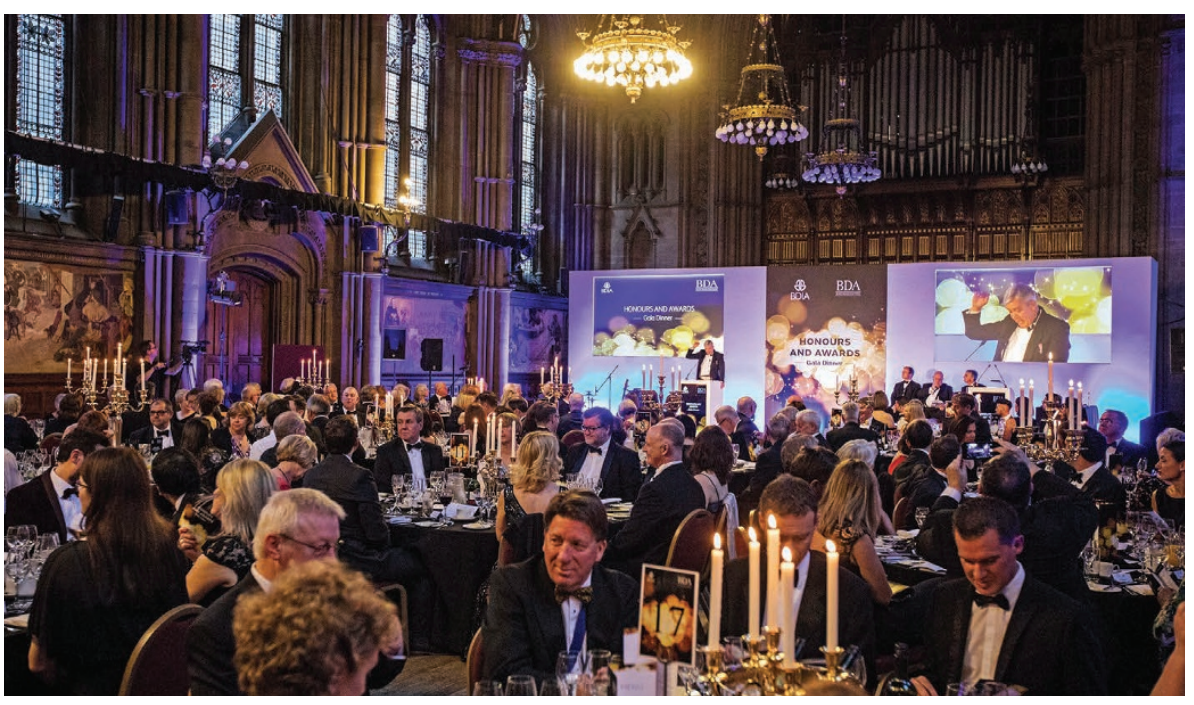

